\title{
1. Publishing in management: exhilaration, bafflement and frustration
}

\section{Mike Wright, David J. Ketchen, Jr. and Timothy Clark}

Scholars find the journal publishing process exhilarating, baffling and frustrating in equal measure. The professional joy and excitement of receiving an acceptance letter following a long drawn-out process in which you have diligently responded to successive rounds of reviewers' comments is probably only matched by a letter awarding a research grant. Contrast this to the sense of dejection and distress that accompanies a rejection letter. This is further exacerbated if the reviewers' comments and decision appear to be harsh and if they make little sense. It is even more disappointing if the paper appears to have been progressing through different rounds of reviewing only to be rejected late in the process. Therefore, we have to start all over again. We may not realize it but academics are not dissimilar to actors in that they constantly have to audition their work in journals or to research funders. Learning to live with rejection is a key part of the role. We cannot be successful with every submission.

\section{THE PUBLISHING LANDSCAPE}

The chances of acceptance are well below 10 per cent at most prestigious journals and they tend to be lower the 'better' the journal. Indeed, there is a familiar adage that if you are not being rejected, you are not aiming high enough. There is increasing pressure on academics to publish in journals, and in what are considered to be the 'right' journals in particular. While individual departments and schools have had internal 'private' journals lists for many years to aid colleagues' decisions when submitting work and to aid assessments of quality at the point of 
recruitment or promotion, a number of 'public' national and international journals lists have gained prominence in recent years. These have increasingly replaced the business and management journal rankings produced by services such as the Web of Science ${ }^{\mathrm{TM}}$.

In the United Kingdom, the Chartered Association of Business Schools created the 'Academic Journal Guide' in 2015 building on the 'ABS Guide 2010'. This ranked journals from across the spectrum of business and management subject areas under five categories ranging from $4 *$ ('journals of distinction', JODs) to 1 (journals of 'modest standard') based on a combination of metrics and consultation with expert peers and scholarly associations. A revised version was published in 2018 to include new journals and to ensure consistency in ranking JODs, which meant in some cases identifying JODs in subject areas where they were previously absent. Reflecting the evolving nature of journal quality, a full review of the guide is scheduled for 2021 .

Since 2007, the Australian Business Deans Council has produced successive iterations of its Journal Quality List. The latest version encompassed 2767 journals and rated them $A^{*}$ to C. In France, Centre National de la Recherche Scientifique (CNRS) has produced a 'Journal Ranking in Economics and Management' since 2004. This ranks journals from 1 ('distinguished') to 4 ('low selectivity'). In 2008, the European Science Foundation developed an 'initial' journal list for humanities - the European Reference Index for Humanities (ERIH). Now run by the Norwegian Social Science Data Services (NSD), this was relaunched 2014 as ERIH Plus and has been extended to include the social sciences. Although not an evaluative ranking service, journals are included in accordance with published criteria. The main aims of this initiative are to 'enhance the global visibility of high-quality research in the humanities and social sciences across Europe, and to facilitate access to research journals published in all European languages' (ERIH Plus 2019). Finally, several trade publishers have produced journal lists as part of the intellectual capital or research scores in their Master of Business Administration (MBA) rankings. The most prominent are the lists used by Bloomberg Business Week and the Financial Times.

Given that several of these lists contribute to the rankings of business schools, they have a significant influence on the perceptions of reputations of schools and therefore impact on the scholars whose published work in these journals undergirds their rankings. As two of the editors of this volume noted in an editorial for the Journal of Management Studies (Clark and Wright 2007, p. 613): 
Whereas the ranking of journals in which people publish has always had implications for personal reputation, peer recognition and career advancement, increasingly it is impacting much more directly on institutional reputations and department rankings and in turn on access to resources and potential recruitment of staff and students. Individual publication choices and success are therefore assuming ever greater institutional significance.

To manage institutional reputations, individual business schools are increasingly abandoning their own lists and adopting those mentioned above. As a consequence, scholars in different business schools are being encouraged to submit only to those journals that are more highly ranked on these lists. It comes as no surprise that submission rates, desk rejection rates (that is, rejection by the editors prior to seeking reviewer comments) and overall rejection rates in 'top tier' journals have increased (Judge et al. 2007, p. 501; Monastersky 2005). Indeed, we have experienced such trends during our tenures as editors of different journals, with submission rates increasing significantly, desk rejection rates creeping to over 50 per cent and general acceptance rates dropping to well below 10 per cent (see, for example, Clark and Wright 2007).

Although we lack the hard data needed to draw a firm conclusion, our observation when acting as journal editors over the past two decades is that landing reviewers who are bona fide experts on a journal submission's topic has become increasingly difficult over time. Leading journals are attracting increasing numbers of submissions every year while the pool of available expert reviewers appears to be increasing only slightly if at all. This has created a basic supply-demand imbalance that does not work in authors' favour. A potential result is that any given submission may not be receiving the same calibre of expert vetting as it would have in years past. Relative to 10 or 20 years ago, a paper that you submit today may be assigned to reviewers who are much less experienced and who know far less about your specific topic.

Beyond this systemic macro trend, a quick immersion into the voluminous literature on the peer-review process indicates that there are a number of failings that either individually or in combination may prevent or forestall innovative material from being published in highly regarded journals. In a seminal study on peer review, Peters and Ceci (1982) resubmitted 12 articles to the psychology journals in which they had already been refereed and published 18 to 32 months earlier. To disguise the papers, a number of 'cosmetic' alterations were made to the titles, abstracts and opening paragraphs in the introduction, but their meaning was not changed. In addition, fictitious names for authors and institutional affiliations were used. Nine of the manuscripts were sent out for 
review (three were rejected). Only two of the 18 reviewers recommended that the papers be accepted. Hence, only one article was accepted, with the consequence that one journal made an identical evaluation over the two periods of time. This article generated a voluminous response (over 70 commentaries in the same issue) and provoked heated discussion across different disciplines as to the ability of the review process to determine the level of quality, interestingness, contribution and likely impact of an article under consideration (see, for example, Bedeian 2003; Campanario 1998; Miller 2006; Osterloh and Frey 2015; Starbuck 2003, 2005). Given the critical weaknesses in the review process, it has been questioned by a range of commentators whether superior quality work is published in journals as a consequence of reviewers' comments and, therefore, whether the most able scholars are being hired and promoted on the basis of such published work. This literature highlights three general flaws in the journal review process.

First, reviewers are often accused of being overly harsh in their judgements. They approach manuscripts assiduously looking to expose weaknesses rather than balancing these with an equivalent appreciation of the merits. In a system where the work of others is evaluated anonymously, the incentives to be constructive and polite may lessen. People may communicate more bluntly than they would face to face.

Furthermore, reviews are solicited from people who are invariably busy and have simply added a further task to their already over-committed diaries. In these circumstances, reviewers may adopt a shorthand approach in which they prioritize the finding of faults and weaknesses rather than engaging positively with the ideas, arguments and evidence in the paper from the author's point of view. In addition, as Starbuck (2003) suggests, this approach may in part arise from reviewers seeing themselves as superior to the authors (in their role as reviewers). He comments: 'Occasionally reviewers seem arrogant, disrespectful, even nasty' (Starbuck 2003, p. 344). They believe they know better than the authors and could write a better article. They therefore often see their role as telling the author to write the paper they would write. This can lead to a situation where authors feel their ideas are unappreciated, undervalued and ignored.

Managing reviewers is a key task that falls to editors. In our experience, there are three basic approaches that editors take to this task. 'Posties' (or, in US terminology, mail carriers) simply collect the reviews, add little independent thought or synthesis of reviewers' ideas, pass along reviews to the authors and accept a paper only if the reviewers say to do so. Editors abdicating their authority in this way can be very harmful to authors. For example, authors may feel that they are being forced to write 
the paper the reviewers want them to write or respond to points that are superficial, misguided or just wrong. In these circumstances, reviewers may become uninvited ghost writers and/or veto wielders.

In one baffling case, a revision of a conceptual paper was rejected without all of the reviews being received. One reviewer recommended acceptance with no further revisions, a second reviewer vehemently opposed the paper and the third reviewer was not sent the revision owing to an administrative glitch. The action editor based his decision on the fact that the negative reviewer 'was extremely forceful' in his or her comments. After it became known that the third reviewer was not given the opportunity to participate, the action editor refused the authors' request to collect the third review and then revisit his decision. Worse, in the first round of review, the decision letter had been written based on the first two reviews and the third review was sent to the authors about a week later with no effort to reconcile important discrepancies between it and the other reviews. Sure enough, some of the very negative reviewer's key concerns about the revision revolved around material that was added to the paper in order to respond to the third reviewer. Although most 'postie editors' are not as callow and impotent as this, the anecdote illustrates the danger of allowing reviewers to dominate decision-making in the review process.

A much different approach is adopted by 'emperors'. These editors downplay or even disregard the reviews; only their opinions matter, even if they know little about the subject matter. Luckily these people are few and far between. Similar to the emperor in Hans Christian Andersen's legendary fable, however, they resist being told that they have no clothes.

Finally, 'judges' live by the mantra that reviewers review and editors decide. They gather relevant evidence by reading the paper and studying the reviews, analyse the evidence and make informed decisions. This is important because just making decisions by tallying up the reviewers' recommendations regarding revise or reject can be highly misleading as some reviewers may recommend reject yet make many comments that can be addressed, while other reviewers may be extremely negative in their comments yet recommend revision. When revision opportunities are granted, judges synthesize reviewers' input in their decision letters in order to give authors the best opportunity to succeed. Importantly, judges are not afraid to contradict a reviewer in an effort to advance the state of research knowledge. Some editors of this type emphasize that reviewers must 'step into the framework of the authors when evaluating a paper, rather than imposing their preferred framework or perspective on those authors (and thereby asking the authors to write the reviewer's preferred paper)' (Miller and Van de Ven 2015, p. 118, see also Clair 2015). 
Second, ${ }^{1}$ as Peters and Ceci (1982) suggest, a number of factors have been found to bias reviewer judgements (for a full review, see Campanario 1998). Where authors' identities are known, their institutional affiliations and social networks may influence judgements. However, these factors are reduced when a blind review process is used, although not eradicated because with the Internet and electronic dissemination of manuscripts an author's identity is very difficult to hide (see Hillman and Rynes 2007). Here issues such as the apparent complexity of language, use of citations, appropriate jargon, sophisticated statistical procedures, and presentation of positive and significant results that do not merely replicate previous findings have all been found to influence or bias decisions.

Third, and perhaps the area which has received greatest empirical attention, studies in a range of disciplines have consistently reported low overall inter-referee agreement (see Cicchetti 1980, 1991; Gottfredson 1978; Hendrick 1977; Scar and Weber 1978; Scott 1974). Evidence within management studies is more scant. Starbuck (2003) reports a study he undertook while editor of Administrative Science Quarterly. An examination of 500 pairs of reviews revealed a correlation of 0.12 . He concluded that 'It was so low that knowing what one reviewer had said about a manuscript would tell me almost nothing about what a second reviewer had said or would say' (Starbuck 2003, p. 346).

\section{TOWARD RIGOR AND RELEVANCE}

Concerns about journal lists and the nature of the review process have contributed to a heated debate about the journal publishing and academic evaluation system (see, for example, the exchange between Harley 2019 and Phillips 2019; see also Tourish 2019). A further dimension of the debate relates to concerns that pressure to publish in top journals is taking management research away from relevance for practice and policy. The two are not necessarily mutually exclusive. Indeed, addressing relevance to practice and policy can create a virtuous circle of identifying more interesting research questions that can help with getting into top journals.

A brief anecdote offers an illustration of a virtuous circle. One of this volume's co-editors was approached by a former MBA student about helping his employer win a defence contract that was currently held by an industry leader. The MBA alumnus believed that academic concepts and frameworks could be the differentiator that would lead his company to victory in the open-bid process. With the help of a six-doctorate $(\mathrm{PhD})$ 
consulting team, the MBA alumnus's company won the 10-year, \$11.2 billion contract. However, the story does not end there. Insights obtained via the consulting project fuelled articles that appeared in Journal of Operations Management (that is, Ketchen and Hult 2007), Strategic Entrepreneurship Journal (Ketchen et al. 2007) and Business Horizons (Ketchen et al. 2008). In the last of these, two professors, the MBA alumnus and a co-worker at the company collaborated as co-authors. Success via this type of author team might be the ultimate expression of the virtuous circle between theory and practice.

Influencing billion-dollar contracts is rare, but other opportunities for real-world impact abound. There appears to be growing momentum from journal editors, others from various parts of the management discipline (Wiklund et al. 2019) and in neighbouring fields (Craighead et al. 2019) to encourage rigorous submissions that are impactful for practice and policy. Once an article is published, disseminating the knowledge it generates to practitioners and policy-makers via leading business press outlets such at the Financial Times and the Wall Street Journal is a powerful way to complete a virtuous cycle. A dilemma arises here, however, in that the public relations staff at many colleges and universities seem to lack the contacts and skills to place researchers' work in that calibre of outlet. Our experience has been that editors at business press outlets welcome contact from faculty and are willing to work with academics to craft a message that will resonate with their readers. In part, this often involves replacing words such as 'disseminating' and 'resonate' with simpler alternatives.

Looking to the future, real-world impact is likely to increase in importance for faculty. Some evaluation systems, such as the UK's Research Excellence Framework (REF) exercise, now include assessment of impact cases that need to show how international-level research has had an impact on policy and practice (Pidd and Broadbent 2015). For example, one of the co-editors of this volume demonstrated that evidence from their systematic studies of employment and employee relations showed that the impact of private equity investment was more positive than had been portrayed in unrepresentative cases used in media and policy debates (Amess and Wright 2007; Bacon et al. 2010). This evidence influenced the European Parliament to modify its proposals for the regulation of the private equity industry which would otherwise have disadvantaged private equity acquirers compared with corporate acquirers. Details on this and other examples of impact cases can be found in REF (2014).

Whether we like it or not, the nature of academic publishing is that it is a winner-takes-all system; there are no benefits for not publishing, and 
someone who may be only marginally better receives a disproportionate amount of the benefits available (Phillips 2019). In this context, authors need to take every step they can within the confines of professionalism and ethics to maximize their submission's chance of success. Accordingly, this book's chapters are intended to provide actionable advice that authors can leverage. In case our thoughts in this brief introduction are taken as overly pessimistic, we want to stress that we have found the research process to be personally and professionally fulfilling, as have the authors who have contributed to this book. Our hope is that each reader will find one or more tips in the chapters that follow that resonate, will act on these tips and will be better able to place research papers in our discipline's leading journals.

\section{CONTENTS OF THE SECOND EDITION}

We have structured the book in three parts. The book can be read in its entirety, but many readers may prefer to dip into various topics to suit their particular needs. Part I contains general contributions on important aspects of the publishing process. We start in Chapter 2 with an in-depth case study of a paper travelling through the review process which includes the perspectives of the authors, the editor and the reviewers. This chapter sets the scene for the remainder of the book and is followed by a chapter that examines the range of issues arising at different stages in the journal submission and review processes (Chapter 3). Ethics and integrity in academic research has always been important, but it has taken on particular significance in recent years. Accordingly, we devote Chapter 4 specifically to this topic. Since academic careers are not just about getting that first job and then achieving tenure but are also about sustaining publications in the long run, Chapter 5 outlines some strategies for achieving this. Increasingly the focus of attention is on publishing in leading international journals, which are often US based. However, as Chapter 6 shows, using the example of Asia, other contexts can provide opportunities to publish quality research. This chapter discusses the similarities and differences in publishing Asian research in Asian management journals compared with those in North America. Chapter 7 presents insights into the deficiencies of the review process and how authors should consider and approach feedback from reviewers. The three chapters new to this second edition in Part I deal first, in Chapter 8, with the important issues relating to managing your research pipeline to ensure that publishing momentum is maintained, then Chapter 9 addresses issues relating to how to maximize your academic impact, with 
Chapter 10, tackling how to position a paper for publication, providing a bridge to the more specific topics in the subsequent parts of the book.

Part II contains short contributions on specific topics essential to resolving practical key issues in undertaking good research and the preparation of publishable manuscripts. We have organized this part into four sections relating to 'Becoming a Scholar' (Chapters 11-15), 'Getting Your Methods Right' (Chapters 16-18), 'Navigating the Review Process' (Chapters 19-22) and 'Understanding the Journals' (Chapters 23-29). In soliciting these chapters, we encouraged authors to draw on their considerable experience as authors, editors and reviewers to share candid confidences that readers might not obtain elsewhere. The contributors fully embraced this charge and we have found some great 'behind the curtain' tips while editing their chapters.

Part III (Chapters 30-36) contains contributions that address publishing across disciplinary boundaries. This part delves into the challenges of publishing in journals for scholars from other related disciplines, including business history, economics, finance, human resource management, international business and psychology, and for management scholars seeking to publish their work in journals in these areas. Each author presents insights into key issues of difference in the positioning of papers, use and development of theory, data and methods, analysis and discussion of findings and contribution. The authors also identify differences in the review process between management journals and these other areas, and provide specific examples from their own experience.

\section{NOTE}

1. This and the next paragraph are replicated with permission from Clark and Wright (2007).

\section{REFERENCES}

Amess, K. and M. Wright (2007), 'The wage and employment effects of leveraged buyouts in the UK', International Journal of the Economics of Business, 14 (2), 179-95.

Bacon, N., M. Wright, L. Scholes and M. Meuleman (2010), 'Assessing the impact of private equity on industrial relations in Europe', Human Relations, 63 (9), 1343-70.

Bedeian, A.C. (2003), 'The manuscript review process: the proper role of authors, referees, and editors', Journal of Management Inquiry, 12 (4), 331-8. 
Campanario, J. (1998), 'Peer review for journals as it stands today - part 1', Science Communication, 19 (3), 181-211.

Cicchetti, D. (1980), 'Reliability of reviews for the American Psychologist', American Psychologist, 35 (3), 300-303.

Cicchetti, D. (1991), 'The reliability of peer review for manuscript and grant submission: a cross-disciplinary investigation', Behavioral and Brain Sciences, 14 (1), 119-86.

Clair, J.A. (2015), 'Toward a Bill of Rights for manuscript submitters', Academy of Management Learning \& Education, 14 (1), 111-31.

Clark, T. and M. Wright (2007), 'Reviewing journal rankings and revisiting peer reviews: editorial perspectives', Journal of Management Studies, 44 (4), 612-21.

Craighead, C.W., D.J. Ketchen and J.L. Darby (2019), 'Taking AIM at theoretical and pragmatic impact: a call for actionable, insightful, and measurable research', Journal of Business Logistics, online, 17 June, doi:10.1111/ jbl.12214.

European Reference Index for the Humanities and the Social Sciences (ERIH Plus) (2019), 'Background', accessed 8 August 2019 at https://dbh.nsd.uib.no/ publiseringskanaler/erihplus/about/index.

Gottfredson, S. (1978), 'Evaluating psychological research reports: dimensions, reliability and correlates of quality judgements', American Psychologist, 33 (10), 920-34.

Harley, B. (2019), 'Confronting the crisis of confidence in management studies: why senior scholars need to stop setting a bad example', Academy of Management Learning and Education, 18 (2), 286-97.

Hendrick, C. (1977), 'Editorial comment', Personality and Social Psychology Bulletin, 3 (1), 1-2.

Hillman, A. and S. Rynes (2007), 'The future of double-blind review in management', Journal of Management Studies, 44 (4), 622-7.

Judge, T.A., D.M. Cable, A.E Colbert and S.L. Rynes (2007), 'What causes a management article to be cited: article, author, or journal?', Academy of Management Journal, 50 (3), 491-506.

Ketchen, D.J. and G.T. Hult (2007), 'Bridging organization theory and supply chain management: the case of best value supply chains', Journal of Operations Management, 25 (2), 573-80.

Ketchen, D.J., R.D. Ireland and C. Snow (2007), 'Strategic entrepreneurship, collaborative innovation, and wealth creation', Strategic Entrepreneurship Journal, 1 (3-4), 371-85.

Ketchen, D.J., W. Rebarick, G.T. Hult and D. Meyer (2008), 'Best value supply chains: a key competitive weapon for the 21st century', Business Horizons, 51 (3), 235-43.

Miller, C.C. (2006), 'Peer review in the organizational and management sciences: prevalence and effects of reviewer hostility, bias and dissensus', Academy of Management Journal, 49 (3), 425-31.

Miller, C.C. and A.H. Van de Ven (2015), 'Peer review, root canals, and other amazing life events', Academy of Management Discoveries, 1 (2), 117-23. 
Monastersky, R. (2005), 'The number that's devouring science', The Chronicle of Higher Education, 52 (8), A12, accessed 2 December 2015 at http://chronicle. com/free/v52/i08/08a01201.htm.

Osterloh, M. and B.S. Frey (2015), 'Ranking games', Evaluation Review, 39 (1), 102-29.

Peters, D. and S. Ceci (1982), 'Peer-review practices of psychological journals: the fate of published articles, submitted again', Behavioral and Brain Sciences, 5 (2), 187-255.

Phillips, N. (2019), 'What is academic success anyway? A rejoinder to "confronting the crisis of confidence in management studies", Academy of Management Learning and Education, 18 (2), 306-9.

Pidd, M. and J. Broadbent (2015), 'Business and management studies in the 2014 Research Excellence Framework', British Journal of Management, 26 (4), 569-81.

Research Excellence Framework (REF) (2014), 'Impact case studies', accessed 12 August 2019 at http://impact.ref.ac.uk/CaseStudies/Results.aspx?val=business +and+management.

Scar, S. and B. Weber (1978), 'The reliability of reviews for the American Psychologist', American Psychologist, 33, 935.

Scott, W. (1974), 'Interreferee agreement on some characteristics of manuscripts submitted to the Journal of Personality and Social Psychology', American Psychologist, 29 (9), 698-792.

Starbuck, W.H. (2003), 'Turning lemons into lemonade: where is the value in peer review?', Journal of Management Inquiry, 12 (4), 344-51.

Starbuck, W.H. (2005), 'How much better are the most prestigious journals? The statistics of academic publication', Organization Science, 16 (2), 180-200.

Tourish, D. (2019), Management Studies in Crisis: Fraud, Deception and Meaningless Research, Cambridge: Cambridge University Press.

Wiklund, J., M. Wright and S. Zahra (2019), 'Conquering relevance: entrepreneurship research's grand challenge', Entrepreneurship Theory and Practice, 43 (3), 419-36. 